\title{
Comparison of inflammatory markers in induced and spontaneous sputum in a cohort of COPD patients
}

Solveig Tangedal 1*, Marianne Aanerud ${ }^{1}$, Louise JP Persson ${ }^{1}$, Karl A Brokstad ${ }^{2}$, Per S Bakke ${ }^{2}$ and Tomas M Eagan ${ }^{1,2}$

\begin{abstract}
Background: Sputum induction is a non-invasive method for obtaining measurements of inflammation in the airways. Whether spontaneously sampled sputum can be a valid surrogate is unknown. The aim of this study was to compare levels of six inflammatory markers in sputum pairs consisting of induced and spontaneous sputum sampled on the same consultation either in a stable state or during exacerbations of chronic obstructive pulmonary disease (COPD).

Methods: 433 COPD patients aged 40-76, Global initiative for chronic Obstructive Lung Disease (GOLD) stage II-IV were enrolled in 2006/07 and followed every six months for three years. 356 patients were followed for potential exacerbations. Interleukin-6, interleukin-8, interleukin-18, interferon gamma-inducible protein-10, monokine induced by gamma interferon and tumor necrosis factor-alpha (IL-6, IL-8, IL-18, IP-10, MIG and TNF-a) were measured by bead based multiplex immunoassay in 60 paired sputum samples from 45 patients. Albumin was measured by enzyme immunoassay, for concentration correction. Culturing for bacterial growth was performed on 24 samples. Bland-Altman plots were used to assess agreement. The paired non-parametric Wilcoxon signed-rank test, the non-parametric Spearman's rank correlation test and Kruskal-Wallis test were used for statistical analyses. For all analyses, a p-value $<0.05$ was considered significant.

Results: Agreement between the two measurements was generally low for all six markers. TNF-a was significantly higher in spontaneous sputum at exacerbations $(p=0.002)$ and trending higher at the steady state $(p=0.06)$. Correlation coefficients between the levels of markers in induced and spontaneous sputum varied between 0.58 (IL-18) to 0.83 (IP-10). In spontaneous sputum IL-18 and MIG were higher in ex-smokers $(\mathrm{p}<0.05)$. The levels of all markers were higher in GOLD stage III \& IV except for IL-6 in spontaneous sputum and IL-18 in induced sputum, compared with GOLD stage II, although not statistically significant. In spontaneous sputum the levels of IL-6 were significantly higher if Haemophilus influenzae $(\mathrm{HI})$ was not cultured.
\end{abstract}

Conclusion: We observed a low agreement and significant differences in inflammatory markers between induced and spontaneous sputum, both at steady state and exacerbations. We recommend considering sampling method when reporting on inflammatory markers in sputum.

Keywords: COPD, Sputum sampling, Inflammatory markers

\footnotetext{
*Correspondence: stangedal@gmail.com

'Department of Thoracic Medicine, Haukeland University Hospital, Bergen, Norway

Full list of author information is available at the end of the article
}

\section{Biomed Central}

(c) 2014 Tangedal et al.; licensee BioMed Central Ltd. This is an Open Access article distributed under the terms of the Creative Commons Attribution License (http://creativecommons.org/licenses/by/4.0), which permits unrestricted use, distribution, and reproduction in any medium, provided the original work is properly credited. The Creative Commons Public Domain Dedication waiver (http://creativecommons.org/publicdomain/zero/1.0/) applies to the data made available in this article, unless otherwise stated. 


\section{Background}

Chronic obstructive pulmonary disease (COPD) is a chronic inflammatory disease affecting both the airways and lung parenchyma [1]. The increased airway inflammation has been well described, but its role is yet controversial [2]. Obtaining reliable measurements of airway inflammation non-invasively can enable large cohort studies. Biomarkers sampled by methods like exhaled breath condensate and induced sputum have been compared recently [3]. Induced sputum sampling (ISS) is a non-invasive procedure, which has been standardized and used extensively the last 20 years [4]. Nebulized and inhaled saline increases sputum production in the lungs [4]. Induction has been reported to provide sputum samples of sufficient quality for analyses in more than $80 \%$ of asthma and COPD patients [5-8]. In patients with obstructive lung disease, ISS is usually performed in the steady state as it can induce bronchoconstriction $[9,10]$. However, at least one study has shown that it can be done safely also during exacerbations in patients with mild to moderate COPD [11].

An alternative to ISS is spontaneous sputum sampling (SSS). Levels of inflammatory markers and cell counts in spontaneous and induced sputum have been presented without discriminating between the two sampling methods in some studies [12-14]. Two studies have found that cell viability was higher in induced than spontaneous sputum in patients with asthma or COPD $[15,16]$. However, few studies have addressed whether induced and spontaneous sputum sampled from patients with COPD can actually be used interchangeably for analyses of inflammatory markers, as it was pointed to in a review article published as late as in 2013 [17]. More studies on the subject were recommended already in 2002 [4].

The aim of this study was to compare the levels of the six common inflammatory markers interleukin 6,8 \& 18 (IL-6, IL-8 IL-18), interferon gamma-inducible protein10 (IP-10), tumor necrosis factor-alpha (TNF- $\alpha$ ) and monokine induced by gamma interferon (MIG) in paired induced and spontaneous sputum samples collected from COPD patients in the stable state and/or during acute exacerbations. These markers were chosen for different roles in airways inflammation in COPD, as part of the analyses in the Bergen COPD Exacerbation Study. In addition, this study allowed for an assessment of the safety of sputum induction in COPD patients undergoing an exacerbation.

\section{Methods and material Study population}

The Bergen COPD Cohort Study (BCCS) was a three year follow-up of 433 COPD patients from western Norway between 2006 and 2010, previously described in detail [18]. The patients were invited to our study centre every six months, and sputum induction was performed at nearly all visits. Of the 433 COPD patients, 356 patients living in a proximity that meant they belonged to the Bergen hospital district were offered concomitant participation in the Bergen COPD Exacerbation Study (BCES). Patients included in the BCES were given a laminated green-card with detailed instructions regarding potential symptoms of COPD exacerbations and a telephone number to our study nurse. The telephone was open 12 hours per day, seven days a week for the three years the study lasted. Once contact had been made, the study nurse determined whether immediate hospitalization was necessary, or whether a visit with a study physician could be scheduled the next working day. During that visit or at the ward the day after hospitalization, sputum induction was attempted if our study physician determined the event to be a clinical COPD exacerbation, with a formal assessment according to Wedzicha and Donaldsons's definition [19].

Spontaneous sputum samples were collected before the induced sputum sample at the same time point at occasions when the patients presented with abundant sputum. In total 60 sputum pairs of acceptable quality from 45 patients in the stable state $(n=31)$ or during COPD exacerbation $(n=29)$ were available for analysis. Classification into Global initiative for chronic Obstructive Lung Disease (GOLD 2007) stage and information on smoking habits, were based on the baseline visit in the BCCS. All patients provided written informed consent, and both studies were approved by the Norwegian Regional Ethical Committee.

\section{Sputum sampling and processing}

Inductions were performed using an ultrasonic wave nebulizer. Hypertonic saline (3\%) was inhaled seven minutes times three, and sputum was attempted sampled after each inhalation. If however, the patient was evaluated by the study physician as being too clinically obstructive, or if the patient did not want to inhale an increased saline concentration, the physiological saline concentration of $0.9 \%$ was inhaled instead. Of the 60 sputum pairs evaluated, induction was done with $3 \%$ saline in 47 cases, $0.9 \%$ in ten cases, while for three inductions the concentration was not recorded. Spirometric evaluations (Vitalograph S-model Vitalograph Ltd., Buckingham, England at regular visits in the steady state, EasyOne model 2001 Ndd Medizintechnik AG, Zurich, Switzerland at exacerbation visits) were performed after inhalation of 200-400 ug salbutamol prior to induction with saline. Spirometry was then repeated after each inhalation of the saline. The procedure ended if $\mathrm{FEV}_{1}$ declined $20 \%$ or more, if the patient's symptoms worsened, or if the patient did not wish to proceed. If the patient's post-bronchodilator oxygen saturation was $<90 \%$, induction was not performed. 
For the SSS, patients were asked to expectorate in two different cups, and the most purulent sputum was processed. Both types of sputum samples were kept on ice until processed for quality control and storage, usually within 30 minutes. To break disulphide bonds in mucin, $4 \mathrm{ml} \mathrm{di-}$ thiothreitol 0.1\% (DDT) per gram sputum were added [20]. The samples were then homogenized using an Eppendorf homogenizer at $600 \mathrm{rpm}$ for 15 minutes at a temperature of 4 degrees Celsius. Phosphate-buffered saline (PBS) was added, and the sample filtered to increase homogenization. Supernatants were removed after 15 minutes centrifugation at 4 degrees Celsius, $450 \mathrm{~g}$, aliqouted in $0.5 \mathrm{ml}$ tubes, and stored at -80 degrees Celsius. Trained personnel evaluated viability after staining with tryptan blue. For the sputum samples to be considered of acceptable quality there had to be $>1$ million $/ \mathrm{mL}$ cells, $<20 \%$ epithelial cells and the leucocyte viability had to be $>30 \%$. After December 2006, all sputum samples were also cultured at the Department of Microbiology, Haukeland University Hospital.

The sputum samples were analysed for cytokines using the Luminex ${ }^{\circ} \mathrm{xMAP}^{\oplus}$ technology (Luminex Corporation, Austin, Texas). The cytokine assay used was made by combining standards from BioRad (Bio-Plex Pro Human Cytokine Standards Group I 27-Plex \#171-D50001, Lot No 5022130. Bio-Plex Pro Human Cytokine Standards Group II 23-Plex \#171-D10502 Lot No 5015357) and singleplex assays containing beads for analyses of IL-6, IL-8 IL-18, IP10 , TNF- $\alpha$ and MIG. Thus, all six markers were analyzed in simplex. The samples were processed on a Luminex 100 instrument and the results collected and stored by STarStation software version 2.0 (STarStation Software Version 2.0, Applied Cytometry, Sheffield, UK.) The procedure was performed according to the manufacturer's instructions on six separate days in September 2011.

For 58 of the 60 sputum pairs we also had enough material to perform an enzyme immunoassay of levels of albumin in duplex (Albumin Human ELISA kit, ab 108788, Abcam, Cambridge, UK). Albumin was used as a correction factor for concentration differences between the induced and spontaneous sample for each pair in the following way: The induced to spontaneous albumin ratio was calculated for each sputum pair, and the level of each of the six markers in each of the spontaneous sputum samples multiplied by the corresponding ratio. All later statistical analyses were performed both on "corrected" sputum levels and "uncorrected" sputum levels.

\section{Statistical analyses}

Stata 12.0 was used for the statistical analyses (StataCorp. College Station, Texas). Bland-Altman plots were made to assess agreement between the measured levels of the markers in induced and spontaneous sputum pairs. Bland \& Altman advocates using the difference between the two measurements as the central measurement of bias, and the spread of the difference as a measure of limits of agreement [21]. Usually the difference between the measurements is plotted against the mean of the two measurements, with 2 standard deviations (SD) of the difference representing the 95\% limits of agreement. However, sometimes the difference is dependent upon the size of the mean, in which Bland \& Altman advocates plotting on a log scale [22]. This was the case for all six markers in our study.

The inflammatory markers were not normally distributed, hence the paired non-parametric Wilcoxon signedrank test was used to compare levels of the markers and cell viability between spontaneous and induced sputum. For correlation analyses between spontaneous and induced samples the non-parametric Spearman's rank correlation test was used. For comparisons of the levels of inflammatory markers by clinical characteristics, KruskalWallis test was used. For comparisons of $\mathrm{FEV}_{1}$ decline between stable state and exacerbations during inductions, Wilcoxon signed-rank test was used. For all analyses, a p-value of less than 0.05 was considered significant.

\section{Results}

The characteristics of the study population are presented in Table 1. 60 sputum pairs were available from 45 patients, of which 15 of the patients were women. Of the 60 sputum pairs, 31 were sampled during the stable state and 29 during COPD exacerbations (Table 1).

Mean cell viability was $98 \%$ for both the induced and spontaneous sputum samples. Among the induced samples, 2 out of 60 samples had viability below $90 \%$, for the spontaneous samples all were $90 \%$ viable or better.

Of the six inflammatory markers, TNF- $\alpha$ was significantly higher when measured in spontaneous sputum during exacerbations and almost reaching statistical significance in the steady state (Table 2). For the other markers, no clear trend was seen (Table 2).

Bland-Altman plots for all six inflammatory markers on the $\log$ scale are presented in Figure 1. To obtain the limits of agreement the antilog of the two standard deviations were calculated, and these are presented in Table 3 together with the Spearman's rank correlation coefficients. Although the correlation was fair, varying between 0.58 for IL-18 to 0.83 for IP-10, the agreement was quite low for all six inflammatory markers. Since the $95 \%$ limits of agreement were calculated on the log scale, the upper and lower limits represents ratios relative to one. Thus, based on the calculations presented in Table 3, one would expect the measurement of for instance IL- 6 in spontaneous sputum to fall between 6 times higher or 8 times lower than that measured in induced sputum $95 \%$ of the time.

Even though agreement between individual measurements was low, there could be value to the spontaneous samples if the levels of the markers showed the same associations to clinical parameters in spontaneous as in the 
Table 1 Characteristics of the study population

\begin{tabular}{|c|c|c|}
\hline & $\mathbf{n}$ & $\%$ \\
\hline Patients & 45 & \\
\hline Age, mean (range) & $63.4(46-74)$ & \\
\hline \multicolumn{3}{|l|}{ Sex } \\
\hline Women & 15 & 33 \\
\hline Men & 30 & 67 \\
\hline \multicolumn{3}{|l|}{ Smoking habits } \\
\hline Ex & 30 & 67 \\
\hline Current & 15 & 33 \\
\hline \multicolumn{3}{|l|}{ GOLD (2007) stage } \\
\hline$\|$ & 15 & 33 \\
\hline III & 24 & 53 \\
\hline IV & 6 & 13 \\
\hline Patients with one sputum pair ${ }^{* *}$ & 36 & 80 \\
\hline Patients with multiple sputum pairs & 9 & 20 \\
\hline Sputum pairs & 60 & \\
\hline stable state & 31 & 52 \\
\hline during exacerbation & 29 & 48 \\
\hline \multicolumn{3}{|l|}{ H.influenza positive ${ }^{\dagger}$} \\
\hline No & 12 & \\
\hline Yes & 12 & \\
\hline
\end{tabular}

"At inclusion.

${ }^{* *}$ Consisting of one spontaneous and one induced sputum sample.

${ }^{\dagger}$ Detected in induced and/or spontaneous sputum sampled from stable state visits, and/or exacerbations.

induced sputum samples. Potential associations between measured levels of the inflammatory markers in spontaneous and induced samples, and clinical variables are presented in Table 4. There was no consistent difference in levels of any of the six markers between current and exsmokers. However, in the spontaneous samples the measured levels of IL-18 and MIG were significantly higher in ex-smokers, an association not found in the induced samples. For all markers except IL-6 and IL-18, there was a non-significant trend of higher levels in GOLD stage III \& IV compared with GOLD stage II. Importantly however, the pattern was the same for both spontaneous and induced sputum samples. Finally, in the 24 sputum pairs where culture was obtained, we examined which impact Haemophilus influenzae (HI) had on the pattern of the sputum markers. In the spontaneous samples HI was associated with significantly lower levels of IL-6, a difference not found in the induced samples. In addition, we observed that in the spontaneous samples levels of MIG were lower in sputum with $\mathrm{HI}$, whereas the opposite pattern was seen in the induced samples (Table 4).

To assess the safety of induction during exacerbations and the stable state we calculated the decline in $\mathrm{FEV}_{1} \%$ predicted during induction for all COPD patients who underwent inductions both in the BCCS and BCES. For decline in $\mathrm{FEV}_{1} \%$ predicted from post bronchodilation values during induction the relative fall was calculated (thus a fall from $30 \%$ predicted to $20 \%$ predicted will be presented as a $33 \%$ decline). To avoid repeated measurements from the same patient at steady state and/or at exacerbations only one registered induction at the two different disease states was selected for analyses per patient. 63 patients were induced during exacerbation. 33 of the patients were GOLD stage III or IV, while the remaining 30 were GOLD stage II. We found no significant difference in $\mathrm{FEV}_{1} \%$ predicted decline caused by induction related to disease severity $(\mathrm{p}=0.07)$ during exacerbations. When comparing patient groups in the stable state we found that patients with more severe COPD had a statistically larger decline related to induction, than patients with COPD GOLD stage II $(\mathrm{p}<0.001)$. The relative fall was significantly higher during the stable state than during exacerbations $(\mathrm{p}=0.03)$ (Table 5). However, no adverse events followed inductions regardless of disease state and severity, and all patients increased in $\mathrm{FEV}_{1}$ after a rest period and a new inhalation of salbutamol.

Table 2 A comparison of inflammatory markers in induced and spontaneous sputum sampled from the COPD patients at the time; either during a COPD exacerbation or during the stable state

\begin{tabular}{|c|c|c|c|c|c|c|}
\hline & \multicolumn{3}{|c|}{ During a COPD exacerbation $n=28$} & \multicolumn{3}{|c|}{ During the stable state $\mathrm{n}=\mathbf{3 0}$} \\
\hline & $\begin{array}{l}\text { Induced sputum } \\
\text { sample }\end{array}$ & $\begin{array}{l}\text { Spontaneous sputum } \\
\text { sample }\end{array}$ & $\mathbf{p}^{*}$ & $\begin{array}{l}\text { Induced sputum } \\
\text { sample }\end{array}$ & $\begin{array}{l}\text { Spontaneous sputum } \\
\text { sample }\end{array}$ & $\mathrm{p}^{*}$ \\
\hline $\mathrm{IL}-6(\mathrm{pg} / \mathrm{ml})$ median, IQR & 10.0(4.9-26.6) & $10.4(2.8-23.3)$ & 0.29 & $20.5(6.11-43.2)$ & $13.9(2.2-55.2)$ & 0.46 \\
\hline IL-8(pg/ml) median, IQR & 339.7(193.6-663.9) & $344.9(173.9-812.2)$ & 0.77 & $514.2(225.6-1257.2)$ & 3709.9(171.7-976.7) & 0.18 \\
\hline IP-10(pg/ml) & 735.0(205.4-2099.6) & $372.1(218.7-1416.2)$ & 0.15 & $529.0(215.4-2554.8)$ & $362.3(142.0-1393.1)$ & 0.07 \\
\hline $\begin{array}{l}\text { TNF-a }(\mathrm{pg} / \mathrm{ml}) \text { median, } \\
\text { IQR }\end{array}$ & $3.0(0.2-11.8)$ & $6.3(2.0-34.0)$ & 0.002 & $0.9(0-2.4)$ & $1.3(0.2-4.3)$ & 0.06 \\
\hline $\begin{array}{l}\text { IL-18 (pg/ml) median, } \\
\text { IQR }\end{array}$ & $9.2(4.9-12.9)$ & 10.6(3.6-27.3) & 0.52 & $6.5(2.4-25.6)$ & $9.6(0.8-18.2)$ & 0.64 \\
\hline $\begin{array}{l}\text { MIG (pg/ml) median, } \\
\text { IQR }\end{array}$ & 539.2(100.1-1496.0) & 384.6(221.2-1997.0) & 0.41 & $534.4(56.9-1450.1)$ & $567.4(178.0-2031.7)$ & 0.82 \\
\hline
\end{tabular}

"Wilcoxon sign rank test. 

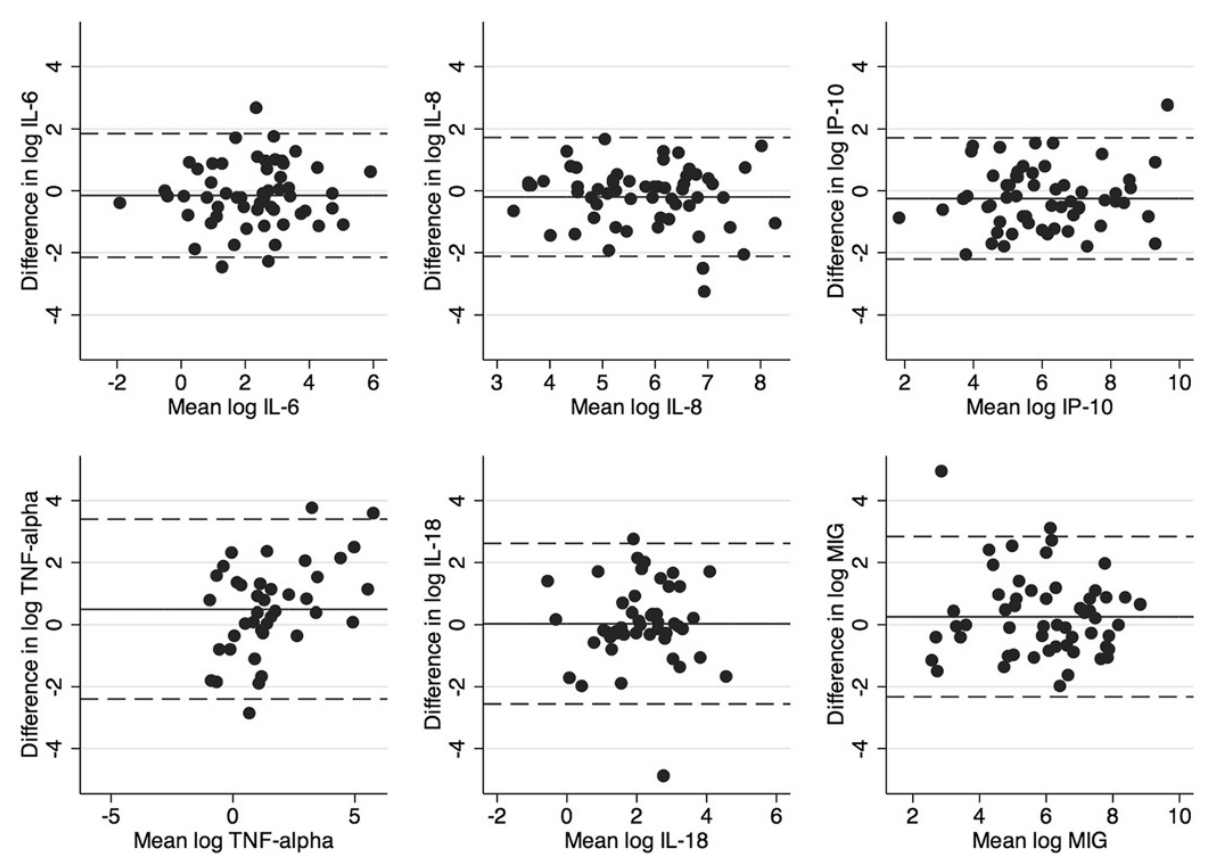

Figure 1 Bland-Altman plots of the agreement between measurements of six inflammatory markers in induced and spontaneous sputum samples.

\section{Discussion}

This study showed that for the six inflammatory markers, the correlation between levels measured in induced and spontaneous sputum pairs was fair, but the agreement was quite low. TNF- $\alpha$ was significantly higher in spontaneous sputum samples than in induced samples when measured during a COPD exacerbation. Further, there was a relationship between HI carrier state and IL6 , and smoking status and IL-18 and MIG, found only in spontaneous sputum samples.

There are some methodological issues to consider. Firstly, it has been shown that both PBS and DTT affect the recovery of some cytokines [12,23]. However, a strength of this study was that the exact same processing protocol was used for all sputum pairs, and this should thus not impact the measured levels differently between spontaneous and induced sputum samples. Secondly, all the inflammatory markers were measured in simplex, thus the potential measurement error is greater than if the markers were measured in duplex. The choice of analysing in simplex was due to cost, since this is part of a larger analysis of inflammatory markers in sputum. Most importantly however, all sputum pairs were analysed on the same plate, on the same day. Thus the measurement error should not differ between spontaneous and induced samples. Thirdly, we found associations between inflammatory markers and smoking, and inflammatory markers and colonization with $\mathrm{HI}$ only in spontaneous sputum. We found no association between inflammatory markers and GOLD stage in either type of sputum, but

Table 3 Rank correlation coefficients and the $\mathbf{9 5 \%}$ limits of agreement between measurements of six inflammatory markers in induced and spontaneous sputum samples

\begin{tabular}{llll}
\hline & \multicolumn{2}{c}{ Correlation coefficient $^{*}$} & \multicolumn{2}{c}{ Bland \& Altmans 95\% limit of agreement $^{\dagger}$} \\
\cline { 3 - 4 } & & Lower & Upper \\
\hline IL-6 $(\mathrm{pg} / \mathrm{ml})$ & 0.729 & 0.12 & 6.35 \\
IL-8 $(\mathrm{pg} / \mathrm{ml})$ & 0.695 & 0.12 & 5.59 \\
IP-10 $(\mathrm{pg} / \mathrm{ml})$ & 0.833 & 0.08 & 13.7 \\
TNFa $(\mathrm{pg} / \mathrm{ml})$ & 0.600 & 0.11 & 5.53 \\
IL-18 $(\mathrm{pg} / \mathrm{ml})$ & 0.583 & 0.09 & 29.99 \\
MIG $(\mathrm{pg} / \mathrm{ml})$ & 0.754 & 0.10 & 17.24 \\
\hline${ }^{*} \mathrm{Spe}$
\end{tabular}

"Spearman's rank correlation test.

${ }^{\dagger} \pm 2 \mathrm{SD}$ of the mean difference between the two measurements. 
Table 4 Median (IQR) values of inflammatory markers in induced and spontaneous sputum samples by smoking, GOLD stage and H. influenzae carrier state

\begin{tabular}{|c|c|c|c|c|c|c|c|c|c|}
\hline & \multicolumn{3}{|l|}{ Smoking status } & \multicolumn{3}{|l|}{ GOLD stage } & \multicolumn{3}{|l|}{ H. influenzae } \\
\hline & Current smoker $n=15$ & Ex-smoker $n=29$ & $\mathrm{p}^{*}$ & II $n=15$ & III+IV n = 29 & $\mathrm{p}^{*}$ & No $n-12$ & Yes $=n=12$ & $\mathrm{p}^{*}$ \\
\hline \multicolumn{10}{|l|}{$\|-6(\mathrm{pg} / \mathrm{ml})$} \\
\hline induced & $17.2(5.7-36.2)$ & $16.7(4.0-43.2)$ & 0.63 & $16.7(4.5-67.8)$ & $19.4(5.2-36.2)$ & 0.78 & $20.7(10.9-49.0)$ & $17.8(1.3-28.6)$ & 0.16 \\
\hline spontaneous & $10.2(3.0-29.5)$ & $21.5(5.8-48.2)$ & 0.22 & $15.6(2.2-64.9)$ & $13.8(4.45 .8)$ & 0.79 & $32.2(22.4-75.38)$ & $12.0(2.6-18.8)$ & 0.01 \\
\hline \multicolumn{10}{|l|}{$\| L-8(p g / m l)$} \\
\hline induced & 505.4(161.3-805.9) & 517.0(193.3-1257.2) & 0.54 & 233.4(170.0-1257.2) & $529.0(224.5-1156.0)$ & 0.37 & $277.6(170.0-649.0)$ & $655.49(274.70-832.70)$ & 0.32 \\
\hline spontaneous & $221.0(165.4-674.4)$ & 405.0(173.2-891.8) & 0.42 & $210.1(112.7-844.1)$ & $546.3(174.7-891.8)$ & 0.18 & $336.9(210.1-734.2)$ & 570.4(265.8-1141.4) & 0.23 \\
\hline \multicolumn{10}{|l|}{$\mid P-10(p g / m l)$} \\
\hline induced & 216.5(130.9-826.2) & 624.3(289.9-1844.9) & 0.08 & $232.5(175.2-748.3)$ & 600.8(216.7-1844.9) & 0.20 & $477.5(175.2-2554.8)$ & $696.1(56.0-1574.1)$ & 0.85 \\
\hline spontaneous & $345.6(124.9-716.5)$ & $461.0(237.5-1361.7)$ & 0.14 & $354.5(129.7-780.1)$ & $448(237.5-1202.0)$ & 0.33 & $491.9(285.2-2269.7)$ & 582.7(180.0-1093.0) & 0.42 \\
\hline \multicolumn{10}{|l|}{$\operatorname{TNF}-a(p g / m l)$} \\
\hline induced & $0.4(0-1.9)$ & $1.5(0-4.8)$ & 0.34 & $0.00(0.00-2.5)$ & $1.6(0-4.2)$ & 0.14 & $2.3(0.0-5.1)$ & $3.2(0.7-24.3)$ & 0.24 \\
\hline spontaneous & $0.9(0-3.2)$ & $3.3(0.3-7.4)$ & 0.20 & $0.5(0.0-4.5)$ & $2.4(0.8-7.4)$ & 0.18 & 6.43.7-14.0 & $7.9(2.1-173.9)$ & 0.69 \\
\hline \multicolumn{10}{|l|}{$\operatorname{lL}-18(\mathrm{pg} / \mathrm{ml})$} \\
\hline induced & $9.0(0.9-19.3)$ & $8.4(4.1-25.6)$ & 0.58 & $10.6(2.4-14.9)$ & $6.3(4.1-25.6)$ & 0.91 & $5.04(0.0-13.6)$ & $4.2(0.6-10.1)$ & 1.0 \\
\hline spontaneous & $2.9(0.5-14.8)$ & $14.8(8.3-31.7)$ & 0.01 & $8.8(1.0-15.1)$ & $14.6(3.5-29.8)$ & 0.24 & $10.4(5.0-13.9)$ & $7.0(2.7-25.2)$ & 0.45 \\
\hline \multicolumn{10}{|l|}{$M I G(p g / m l)$} \\
\hline induced & $332.2(30.1-661.7)$ & 806.3(110.5-1391.4) & 0.15 & $121.8(41.2-897.0)$ & $661.7(110.5-1314.3)$ & 0.27 & 157.8(43.3-1714.8) & $677.1(179.0-961.8)$ & 0.54 \\
\hline spontaneous & 208.5(31.7-385.8) & $626.8(222.6-2031.7)$ & 0.03 & 280.4(69.8-1537.1) & 383.4(205.3-1941.6) & 0.47 & $1473.0(438.8-4392.9)$ & $740.5(384.6-2088.3)$ & 0.33 \\
\hline
\end{tabular}

Kruskal-Wallis test. 
Table 5 Relative FEV $_{1}$ decline in \% predicted during sputum induction

$\begin{array}{ll}\text { Exacerbations } & \text { Steady state } \\ n=63 & n=390\end{array}$

0.004

$\begin{array}{lll}\text { Median }(\mathrm{IQR}) & 12.64(5.56-21.79) & 18.75(11.11-25) \\ \text { Mean (SD) } & 14.80(13.05) & 18.51(11.44)\end{array}$

"Wilcoxon sign rank test.

this may be due to lack of strength. Finally, the choice on whether to induce or not during an exacerbation was based on several subjective factors in addition to oxygen saturation; most importantly patients' willingness to be induced and the clinicians' evaluation regarding obstructivity. Thus, it is impossible from this design to conclude that sputum induction would be safe during all exacerbations.

Although more studies on the subject of whether spontaneous and induced sputum samples could be compared was recommended already in 2002 [4], few studies have yet been published. We have found one earlier report on levels of IL-8 in spontaneous versus induced sputum that showed no significant differences in IL-8 levels between the two sputum types in COPD patients in stable state [16]. Our study confirmed the results from this earlier study, but in addition we were able to show that this is true also during exacerbations. We have been unable to find earlier reports on the relationship between levels of inflammatory markers in spontaneous and induced sputum for the remaining five inflammatory markers. To our knowledge comparison of other inflammatory markers in induced and spontaneous sputum sampled on the same consultation has not been performed in patients with obstructive pulmonary disease.

It has previously been shown that the sputum sampled early during induction has a different consistency and cell composition than sputum sampled late in the induction $[24,25]$. It is likely that more central airways are sampled early, and would thus most resemble spontaneous sputum. Thus, induced sputum is likely to sample a more distal airways environment than spontaneous sputum. Central and distal airways differ by epithelial components [26], distribution of immune cells [27,28], and possibly respiratory microbiome [29]. Thus, it is theoretically rather likely that levels of inflammatory markers differ between spontaneous and induced sputum samples. However, one can argue that spontaneous sputum could be a favorable alternative to induced sputum when patients find induction uncomfortable, or the safety of the induction is uncertain, and enable sampling in primary healthcare settings where induction is rarely if ever performed to our knowledge. Cell viability in spontaneous sputum has in some studies been shown to be poorer than in induced sputum samples $[15,16]$. Such was not the case in our samples, where viability was as good in the spontaneous samples as in the induced samples. In our study the time from collection to processing was usually very short, which could explain the high viability.

Although agreement for individual measurements was low, measuring levels of inflammatory markers in spontaneous sputum could have value for instance in serial measurements of spontaneous sputum, something our study is not equipped to assess. Also, although comparisons of inflammatory markers between spontaneous and induced sputum is invalid for some markers, they may be valid for others.

There are still sparse data on the safety on induction in patients with severe COPD during exacerbations, and in several studies sputum induction is performed during exacerbation without the published reporting on potential adverse effects on the procedure [3,30,31].

In our study we found statistical differences in $\mathrm{FEV}_{1} \%$ predicted decline between patients with moderate and severe/very severe COPD only during steady state, while disease severity did not affect the decline during exacerbations. No adverse events were registered during either the steady state or during exacerbations. This is in accordance with other reports $[7,11]$, but we expand by including patients with severe/very severe COPD. However, it should be stressed that necessary precautions need to be taken such as having access to acute rescue medications, and that all inductions only should be performed by trained medical personnel [32].

The results from the current study point toward a necessity for reporting on sampling methods when considering inflammatory markers in sputum samples collected from COPD patients both during the steady state and during acute exacerbations as the agreement was generally low as assessed by Bland \& Altman's 95\% limits of agreement. Whether levels of inflammatory markers can be compared between spontaneous and induced sputum samples likely differ by each inflammatory marker in question, and should be addressed within each study. In cases where induced sputum sampling is impossible, spontaneous samples may have value if compared with other spontaneous samples.

\footnotetext{
Abbreviations

BCCS: Bergen COPD cohort study; BCES: Bergen COPD exacerbation study; COPD: Chronic obstructive pulmonary disease; DDT: Dithiothreitol;

GOLD: Global initiative for chronic obstructive lung disease; HI: Haemophilus influenza; IL-6: Interleukin 6; IL-8: Interleukin 8; IL-18: Interleukin 18; IP-10: Interferon gamma-inducible protein-10; MIG, Monokine induced by gamma interferon; ISS: Induced sputum sampling; PBS: Phosphate-buffered saline; SSS: Spontaneous sputum sampling; TNF-a: Tumornecrosis factoralpha.
}

Competing interests

The authors declare that they have no competing interests. 


\section{Authors' contributions}

Study concept and design: ST, TME, MA, PSB. Acquisition of data: ST, MA, LJPP, PSB, TME. Analysis and interpretation of data: ST, MA, KAB, TME. Drafting of the manuscript: ST, TME. Critical revision of the manuscript for important intellectual content: MA, LJPP, KAB, PSB. All authors read and approved of the final manuscript.

\section{Acknowledgements}

The authors wish to thank study nurse Margrete Klemmetsby, physiotherapist Marie Waatevik, microbiologist Dag Harald Skutlaberg, bioengineers Lene Svendsen and Tina Endresen-Vinsjevik for invaluable support during data collection, and Rune Grønseth for help with the Bland Altman analyses.

\section{Author details}

${ }^{1}$ Department of Thoracic Medicine, Haukeland University Hospital, Bergen, Norway. ${ }^{2}$ Institute of Clinical Science, Faculty of Medicine, University of Bergen, Bergen, Norway.

Received: 14 April 2014 Revised: 26 September 2014

Accepted: 24 October 2014

Published online: 15 November 2014

\section{References}

1. Global Strategy for the Diagnosis, Management and Prevention of COPD, Global Initiative for Chronic Obstructive Lung Disease (GOLD) 2014. [http://www.goldcopd.com/guidelines-global-strategy-for-diagnosismanagement.html]

2. Brusasco V, Crimi E, Pellegrino R: Airway inflammation in COPD: friend or foe? Am J Respir Crit Care Med 2007, 176:425-426.

3. Warwick G, Thomas PS, Yates DH: Non-invasive biomarkers in exacerbations of obstructive lung disease. Respirology 2013, 18:874-884.

4. Paggiaro PL, Chanez P, Holz O, Ind PW, Djukanovic R, Maestrelli P, Sterk PJ: Sputum induction. Eur Respir J Suppl 2002, 37:3s-8s.

5. Dragonieri S, Tongoussouva O, Zanini A, Imperatori A, Spanevello A: Markers of airway inflammation in pulmonary diseases assessed by induced sputum. Monaldi Arch Chest Dis 2009, 71:119-126.

6. Wark PA, Simpson JL, Hensley MJ, Gibson PG: Safety of sputum induction with isotonic saline in adults with acute severe asthma. Clin Exp Allergy 2001, 31:1745-1753.

7. Gao P, Gibson PG, Zhang J, He X, Hao Y, Li P, Liu H: The safety of sputum induction in adults with acute exacerbation of COPD. Clin Respir J 2013, 7:101-109.

8. Tsoumakidou M, Tzanakis N, Siafakas NM: Induced sputum in the investigation of airway inflammation of COPD. Respir Med 2003, 97:863-871.

9. Makris D, Tzanakis N, Moschandreas J, Siafakas NM: Dyspnea assessment and adverse events during sputum induction in COPD. BMC Pulm Med 2006, 6:17.

10. Taube C, Holz O, Mucke M, Jorres RA, Magnussen H: Airway response to inhaled hypertonic saline in patients with moderate to severe chronic obstructive pulmonary disease. Am J Respir Crit Care Med 2001, 164:1810-1815.

11. Bathoorn E, Liesker J, Postma D, Koeter G, van Oosterhout AJ, Kerstjens HA: Safety of sputum induction during exacerbations of COPD. Chest 2007, 131:432-438.

12. Bafadhel M, McCormick M, Saha S, McKenna S, Shelley M, Hargadon B, Mistry V, Reid C, Parker D, Dodson P, Jenkins M, Lloyd A, Rugman P, Newbold P, Brightling CE: Profiling of sputum inflammatory mediators in asthma and chronic obstructive pulmonary disease. Respiration 2012, 83:36-44.

13. Wallace J, D'Silva L, Brannan J, Hargreave FE, Kanaroglou P, Nair P: Association between proximity to major roads and sputum cell counts. Can Respir J 2011, 18:13-18.

14. Ronchi MC, Piragino C, Rosi E, Amendola M, Duranti R, Scano G: Role of sputum differential cell count in detecting airway inflammation in patients with chronic bronchial asthma or COPD. Thorax 1996, 51:1000-1004

15. Pizzichini MM, Popov TA, Efthimiadis A, Hussack P, Evans S, Pizzichini E, Dolovich J, Hargreave FE: Spontaneous and induced sputum to measure indices of airway inflammation in asthma. Am J Respir Crit Care Med 1996, 154:866-869.

16. Bhowmik A, Seemungal TA, Sapsford RJ, Devalia JL, Wedzicha JA: Comparison of spontaneous and induced sputum for investigation of airway inflammation in chronic obstructive pulmonary disease. Thorax 1998, 53:953-956.

17. Koutsokera A, Kostikas K, Nicod LP, Fitting JW: Pulmonary biomarkers in COPD exacerbations: a systematic review. Respir Res 2013, 14:111.

18. Eagan TM, Ueland T, Wagner PD, Hardie JA, Mollnes TE, Damas JK, Aukrust $P$, Bakke PS: Systemic inflammatory markers in COPD: results from the Bergen COPD Cohort Study. Eur Respir J 2010, 35:540-548.

19. Seemungal TA, Donaldson GC, Bhowmik A, Jeffries DJ, Wedzicha JA: Time course and recovery of exacerbations in patients with chronic obstructive pulmonary disease. Am J Respir Crit Care Med 2000, 161:1608-1613.

20. Efthimiadis A, Spanevello A, Hamid Q, Kelly MM, Linden M, Louis R, Pizzichini MM, Pizzichini E, Ronchi C, Van Overvel F, Djukanovic R: Methods of sputum processing for cell counts, immunocytochemistry and in situ hybridisation. Eur Respir J Supp/ 2002, 37:19s-23s.

21. Bland JM, Altman DG: Statistical methods for assessing agreement between two methods of clinical measurement. Lancet 1986, 1:307-310.

22. Bland JM, Altman DG: Measuring agreement in method comparison studies. Stat Methods Med Res 1999, 8:135-160

23. Woolhouse IS, Bayley DL, Stockley RA: Effect of sputum processing with dithiothreitol on the detection of inflammatory mediators in chronic bronchitis and bronchiectasis. Thorax 2002, 57:667-671.

24. Holz O, Jorres RA, Koschyk S, Speckin P, Welker L, Magnussen H: Changes in sputum composition during sputum induction in healthy and asthmatic subjects. Clin Exp Allergy 1998, 28:284-292.

25. Gershman NH, Liu H, Wong HH, Liu JT, Fahy JV: Fractional analysis of sequential induced sputum samples during sputum induction: evidence that different lung compartments are sampled at different time points. J Allergy Clin Immunol 1999, 104:322-328.

26. Rackley CR, Stripp BR: Building and maintaining the epithelium of the lung. J Clin Invest 2012, 122:2724-2730.

27. Moodley YP, Krishnan V, Lalloo UG: Neutrophils in induced sputum arise from central airways. Eur Respir J 2000, 15:36-40.

28. O'Donnell R, Breen D, Wilson S, Djukanovic R: Inflammatory cells in the airways in COPD. Thorax 2006, 61:448-454.

29. Erb-Downward JR, Thompson DL, Han MK, Freeman CM, McCloskey L, Schmidt LA, Young VB, Toews GB, Curtis JL, Sundaram B, Martinez FJ, Huffnagle GB: Analysis of the lung microbiome in the "healthy" smoker and in COPD. PLoS One 2011, 6:e16384.

30. Perera WR, Hurst JR, Wilkinson TM, Sapsford RJ, Mullerova H, Donaldson GC, Wedzicha JA: Inflammatory changes, recovery and recurrence at COPD exacerbation. Eur Respir J 2007, 29:527-534.

31. Kersul AL, Iglesias A, Rios A, Noguera A, Forteza A, Serra E, Agusti A, Cosio BG: Molecular mechanisms of inflammation during exacerbations of chronic obstructive pulmonary disease. Arch Bronconeumol 2011 47:176-183.

32. Pizzichini E, Pizzichini MM, Leigh R, Djukanovic R, Sterk PJ: Safety of sputum induction. Eur Respir J Supp/ 2002, 37:9s-18s

\section{doi:10.1186/s12931-014-0138-6}

Cite this article as: Tangedal et al:: Comparison of inflammatory markers in induced and spontaneous sputum in a cohort of COPD patients. Respiratory Research 2014 15:138. 